\title{
Impact of solar energy demonstration project on public - responses of some Finnish citizens living in Eko-Viikki residential area in Helsinki
}

\author{
Md. Abdul Hai
}

\begin{abstract}
Although many studies conducted hitherto concentrated mostly on how demonstration projects affect technological proofs, there is a lacuna to address their effects on innovation diffusion in terms of public acceptance who observe and/or initially experience those. Taking Eko-Viikki residential area with some solar integrated buildings in Helsinki as a case study this paper addresses whether demonstrations can have any impact among people to adopt clean energy technologies such as solar energy. What the people living in some of those solar integrated buildings feel about the technology; and how such demonstrations and initial adoption by the residents of those buildings formed the emulation tendency among people are matters of concentration in this study. Due to unfavourable weather condition solar energy has long been considered nonfeasible by the common Finnish citizens. To meet the huge demand of energy for space heating and electricity, traditional power supply has been playing the major role. This study explores whether the demonstration of those solar integrated buildings for space heating and power generation in Eko-Viikki has brought any change in the mind-set and activities among surrounding people or not. By applying demonstration effect theory (i.e., emulation tendency among people by observing demonstrations and initial adopters) and using semi-structured interview method, this qualitative study was conducted on some Finnish residents of that community to satisfy those queries.
\end{abstract}

Keywords-Solar energy, demonstration effects, social acceptance, emulation, diffusion of innovation.

\section{Declaratoin}

The accepted abstract is presented here and the main article will be written in suitable time and will be published in relevant journal where the key themes of this abstract would remain the same.

\section{Acknowledgment}

The grant received from the Academy of Finland (grant number: 286468) is acknowledged.

Md. Abdul Hai

University of Helsinki

Finland

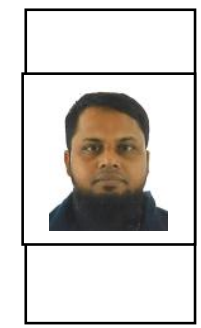

What the people living in some of the solar integrated buildings in Eko-Viikki feel about the technology; and how such demonstrations and initial adoption by the residents of those buildings formed the emulation tendency among people are matters of concentration in this study. 